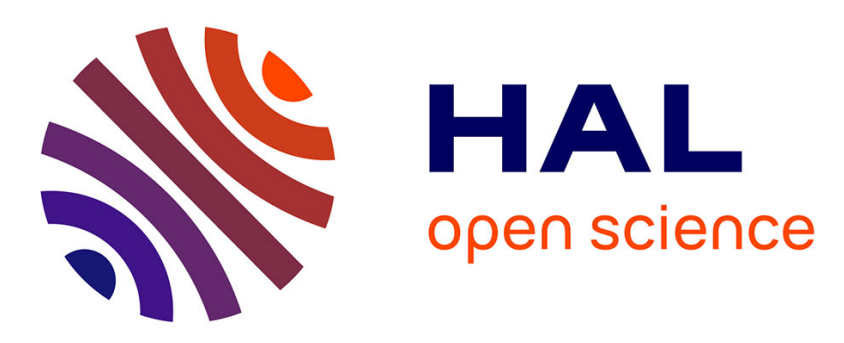

\title{
BacAnalytics: A Tool to Support Secondary School Examination in France
}

\author{
Azim Roussanaly, Marharyta Aleksandrova, Anne Boyer
}

\section{To cite this version:}

Azim Roussanaly, Marharyta Aleksandrova, Anne Boyer. BacAnalytics: A Tool to Support Secondary School Examination in France. 25th International Symposium on Methodologies for Intelligent Systems (ISMIS 2020), Sep 2020, Online Event, Germany. hal-03020852

HAL Id: hal-03020852

https://hal.inria.fr/hal-03020852

Submitted on 24 Nov 2020

HAL is a multi-disciplinary open access archive for the deposit and dissemination of scientific research documents, whether they are published or not. The documents may come from teaching and research institutions in France or abroad, or from public or private research centers.
L'archive ouverte pluridisciplinaire HAL, est destinée au dépôt et à la diffusion de documents scientifiques de niveau recherche, publiés ou non, émanant des établissements d'enseignement et de recherche français ou étrangers, des laboratoires publics ou privés. 


\title{
BacAnalytics: A Tool to Support Secondary School Examination in France
}

\author{
Azim Roussanaly ${ }^{1}$, Marharyta Aleksandrova $^{2}$, and Anne Boyer ${ }^{1}$ \\ 1 University of Lorraine - LORIA, Vandoeuvre-lès-Nancy 54506, France \\ \{azim.roussanaly, anne.boyer\}@loria.fr \\ kiwi.loria.fr/members \\ 2 University of Luxembourg, Esch-sur-Alzette L-4365, Luxembourg \\ marharyta.aleksandrova@\{uni.lu,gmail.com $\}$ \\ secan-lab.uni.lu/marharyta-aleksandrova
}

\begin{abstract}
Students who failed the final examination in the secondary school in France (known as baccalauréat or baccalaureate) can improve their scores by passing a remedial test. This test consists of two oral examinations in two subjects of the student's choice. Students announce their choice on the day of the remedial test. Additionally, the secondary education system in France is quite complex. There exist several types of baccalaureate consisting of various streams. Depending upon the stream students belong to, they have different subjects allowed to be taken during the remedial test and different coefficients associated with each of them. In this context, it becomes difficult to estimate the number of professors of each subject required for the examination. Thereby, the general practice of remedial test organization is to mobilize a large number of professors. In this paper, we present BacAnalytics - a tool that was developed to assist the rectorate of secondary schools with the organization of remedial tests for the baccalaureate. Given profiles of students and their choices of subjects for previous years, this tool builds a predictive model and estimates the number of required professors for the current year. In the paper, we present the architecture of the tool, analyze its performance, and describe its usage by the rectorate of the Academy of Nancy-Metz in Grand Est region of France in the years 2018 and 2019. BacAnalytics achieves almost $100 \%$ of prediction accuracy with approximately $25 \%$ of redundancy and was awarded a French national prize Impulsions 2018.
\end{abstract}

Keywords: Academic analytics - Secondary school examination - Baccalauréat · Classification.

\section{Introduction}

Nowadays, data analytics is used in numerous fields of human activities varying from more technical, such as energy management [12], transportation [13] and online fraud detection [8], to those including management of human resources [4]. Successful adoption of analytical tools in business and marketing impelled the 
usage of data analytics in education as well $[1,10]$. Data analytics usage in education defines 3 research directions: learning analytics (LA), educational data mining (EDM) and academic analytics [11,9]. Both LA and EDM aim to understand how students learn, with EDM having a primary focus on automated model discovery and LA having a stronger focus on keeping a human in the loop. The goal of academic analytics is to support institutional, operational and financial decision making. Academic analytics tools can be designed to assist in various tasks, such as identification of students at risk of failure [6,5], curriculum planning [7], organization of campus life services [3], building competency-based education courses [2] etc.

In this paper, we present a tool design to support the organization of the final examination in French secondary schools. French students who failed secondary school examination (known as baccalauréat or colloquially as $B A C$ ) are allowed to pass a remedial test. This test consists of oral examinations in two subjects of students' choice. Students announce their choices on the day of the remedial examination, which makes it impossible to calculate in advance the number of professors required to examine all students. Given the sensitive nature of the application, the general practice of academic rectorate is to mobilize a large number of professors. Our work presents BacAnalytics - a tool designed to estimate the required number of academic staff. To the best of our knowledge, this problem was not tackled in the literature before.

The rest of the paper is organized as follows. In section 2, we describe the system of baccalauréat examination and the data and information that we used to construct the BacAnalytics tool. In Section 3, we present the architecture of the tool, its evaluation and impact. Finally, we conclude our work in Section 4.

\section{Baccalauréat: Secondary School Examination in France}

\subsection{Baccalauréat organization}

Secondary education in France is finalized with a baccalaureate examination. Unlike final examinations in secondary schools of other countries, BAC is not mandatory and it servers not for school completion, but for university entrance. There are 3 type of BAC: baccalauréat général ${ }^{3}$ (general baccalaureate, BGN),

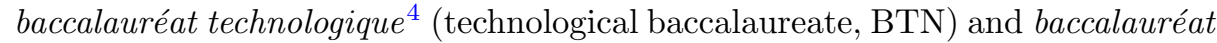
professionnel $^{5}$ (professional baccalaureate), see Table 1. Each type of BAC has multiple streams and many streams have multiple specializations. For example, stream STMG of BTN has 4 specializations: $G F$ - finance management, $M E$ - fast-moving consumer goods management, $R C$ - communication and human resources, and $S I$ - management information systems. Contrarily, stream ST2S has no specializations. Such a system allows providing specialized education for

\footnotetext{
3 https://eduscol.education.fr/cid46205/presentation-du-baccalaureat-general.html

${ }^{4}$ https://eduscol.education.fr/cid46806/epreuves-du-baccalaureat-technologique.h tml

${ }^{5}$ https://eduscol.education.fr/cid47640/le-baccalaureat-professionnel.html
} 
Table 1: Types of baccalaureate.

\begin{tabular}{|c|c|}
\hline Type & Stream \\
\hline 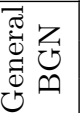 & $\begin{aligned} \text { S } & - \text { Scientific } \\
\text { ES } & - \text { Economics and Social Sciences } \\
\text { L } & - \text { Literature }\end{aligned}$ \\
\hline 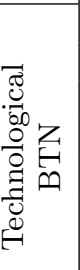 & $\begin{array}{l}\text { ST2S - Sciences and Technologies of Health Care } \\
\text { STI2D - Sciences and Technologies of Industry and Sustainable Development } \\
\text { STL - Sciences and Technology of Laboratory } \\
\text { STMG - Sciences and Technologies of Management } \\
\text { STD2A - Sciences and Technologies of Design and Applied Arts } \\
\text { STHR - Hospitality Industry and Business (before HOT) } \\
\text { TMD - Techniques of Danse and Music }\end{array}$ \\
\hline \multicolumn{2}{|r|}{ Professional baccalaureate: $>100$ specialisations } \\
\hline
\end{tabular}

students with different needs and desires. For instance, professional baccalaureate is designed to prepare students for professional activities right after the school completion. At the same time, the vast majority of students sitting for technological and general baccalaureate continue their studies as senior technicians $(\mathrm{BTN})$ or at universities (BGN).

$\mathrm{BAC}$ consists of both oral and written exams in various subjects and each of them scores between 0 and 20. The set of subjects and associated weights depends on the type of BAC. Most of the subjects can be retaken during the remedial test. The list of subjects that can be retaken and their corresponding weights for BGN and some streams of BTN are presented in Table 2. Some of the subjects are the same for all students of the same stream (part of the table general), and others depend on the chosen specialization (part of the table specialization). The system of weights allows some subjects to be more important than others. Naturally, students usually study more for exams that carry heavier weights since the grade that they obtain in these exams have a bigger impact on their mean grade. The latter determines whether or not one passes the BAC. Students who average between 8 and 10 are permitted to sit for the remedial test (also called the 2-d group as opposite to the initial 1-st group examination). This is a supplementary oral examination, which is given in two subjects of the student's choice. Students announce their choices on the day of the examination, which does not allow calculating in advance the required number of professors.

\subsection{Dataset}

In order to overcome this problem, we collaborated with the Academy of Nancy$M \mathrm{Mtz}^{6}$ of the French region Grand Est. They provided us with the anonymized historical information about students who took the remedial test of baccalauréat for BGN and some streams of BTN. The streams of BTN that were not considered in this work are presented in italics in Table 1 . The distribution of the

\footnotetext{
${ }^{6}$ http://www.ac-nancy-metz.fr/
} 
Table 2: Subjects that can be taken in remedial examination and their weights.

\begin{tabular}{|c|c|c|c|c|c|c|c|c|c|c|}
\hline \multicolumn{8}{|c|}{ General } & \multicolumn{3}{|c|}{ Specialization } \\
\hline \multirow{2}{*}{ Subject } & \multicolumn{7}{|c|}{ Stream \& weight } & $q$ & \multirow{3}{*}{\multicolumn{2}{|c|}{ Subject \& weight }} \\
\hline & $\begin{array}{ll}\mathrm{S} & \mathrm{I}\end{array}$ & $\mathrm{ES}$ & $\mathrm{L}$ & ST2 & $\overline{\mathrm{TI} 2}$ & $\overline{\mathrm{ST}}$ & TMG & 党 & & \\
\hline FRANCAIS(7) ${ }^{* *}$ & 2 & 2 & 3 & 2 & 2 & 2 & 2 & $\bar{E}$ & & \\
\hline HIST.GEOG. & 3 & 5 & 4 & 2 & 2 & 2 & 2 & & ECO.AGR.TER.O & $7 / 9$ \\
\hline PHILOSOPHIE & 3 & 4 & 7 & 2 & 2 & 2 & 2 & U & SC. INGENIEUR & $6 / 8$ \\
\hline LANGUE VIV. 1 & 3 & 3 & $4 / 8^{*}$ & 2 & 2 & 2 & 3 & & SC. VIE TERRE & $6 / 8$ \\
\hline LANGUE VIV. 2 & 2 & 2 & $4 / 8$ & 2 & 2 & 2 & 2 & $\Omega$ & SES - ECO APP & 2 \\
\hline MATHEMAT. & $7 / 95$ & $5 / 7$ & . & 3 & 4 & 4 & 3 & 王 & SES - SC S PO & 2 \\
\hline PHYS-CHIMIE & $6 / 8$ & 7 & . & . & 4 & 4 & . & & MATHEMAT. & 4 \\
\hline SCIENCES & & 2 & 2 & $\cdot$ & $\cdot$ & • & . & & LCA LATIN & 4 \\
\hline SC.ECO. SOC.(7) & . & $7 / 9$ & . & . & . & · & . & & LCA GREC & 4 \\
\hline LITTERATURE & . & . & 4 & . & . & 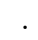 & . & & $\operatorname{ARTS}(7)$ & 6 \\
\hline BIOL.PHYS.H.(6) & . & . & . & 7 & $\cdot$ & $\cdot$ & . & $\theta$ & BIOTECHNOL. & 8 \\
\hline SC.TEC.SAN.S(6) & . & . & . & 7 & . & . & . & En & SPCL & 8 \\
\hline SCI.PHYS.CH.(6) & . & . & . & 3 & . & 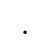 & $\cdot$ & & GESTI.FINAN.(6) & 12 \\
\hline ENS TECH TR(4) & . & - & . & . & 8 & . & . & 遂 & MERCATIQUE(6) & 12 \\
\hline ECO.-DROIT & . & . & . & & . & . & 5 & $G$ & RH.COMMUN.(6) & 12 \\
\hline MANAG.ORGAN. & . & . & . & . & . & . & 5 & & SYST.INFO.G.(6) & 12 \\
\hline
\end{tabular}

* Weight depends on the chosen specialization.

** Number of students a professor can examine during a one-day session (if not specified, the number of students is equal to 9 ).

number of students of the 2-d group from our dataset by years and types and streams of BAC is presented in Fig. 1. The collaboration started in 2017 and in 2018 and 2019 BacAnalytics was tested in field conditions. In this paper, we discuss in details the tool's performance for 2018. Additionally, we present the final results from 2019 to support our closing conclusion.

The provided dataset contains general information about students and their performance in the 1-st group examination, see Table 3 for an example. For every student, we know his/her unique id, examination year, type, stream and specialization of baccalaureate, associated geographical center for the remedial test, the 2 subjects chosen for the remedial test and the resulting grades (see left part of Table 3). Additionally, we know how well every student performed in the 1-st group examination, e.g. we know what grades he/she got for every subject (right part of Table 3). BacAnalytics tool was developed based on this dataset and the general information about the organization of BAC presented in the previous section. In the next section, we describe the tool's architecture, discuss its evaluation and impact.

\section{BacAnalytics tool}

\subsection{Architecture}

The general architecture of the BacAnalytics tool is presented in Fig. 2. We start with a construction of a model for predicting students' choices. In this work we 

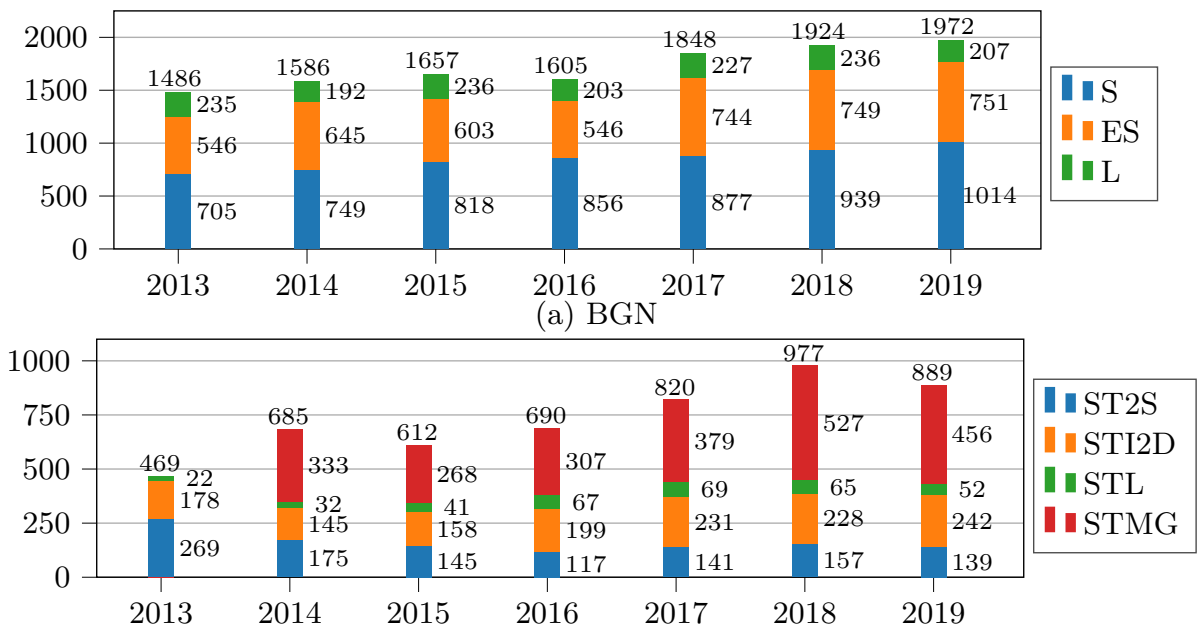

(b) BTN

Fig. 1: Number of students of the 2-d group per year.

Table 3: Example of the dataset with information about students.

\begin{tabular}{|llllllllll||lll|}
\hline \multicolumn{7}{|c||}{ Information about students } & \multicolumn{3}{c|}{ Performance } \\
\hline id & year & type & stream spec. center & choice\#1 & grade choice\#2 & grade & id & subject grade \\
\hline 1 & 2013 & BTN & ST2S & & $054 \mathrm{G}$ & subj.3 & 11 & subj.1 & 12 & 1 & subj.1 & $g_{1}^{1}$ \\
2 & 2013 & BTN & STMG ME & $057 Z$ & subj.1 & 13 & subj.7 & 9 & 1 & subj.2 & $g_{1}^{2}$ \\
$\ldots$ & $\ldots$ & $\ldots$ & $\ldots$ & $\ldots$ & $\ldots$ & $\ldots$ & $\ldots$ & $\ldots$ & $\ldots$ & 1 & subj.3 & $g_{1}^{3}$ \\
127 & 2015 & BGN ES & & $088 G$ & subj.2 & 8 & subj.5 & 9 & $\ldots$ & $\ldots$ & $\ldots$ \\
$\ldots$ & $\ldots$ & $\ldots$ & $\ldots$ & $\ldots$ & $\ldots$ & $\ldots$ & $\ldots$ & $\ldots$ & $\ldots$ & 127 & subj.1 & $g_{127}^{1}$ \\
$\ldots$ & $\ldots$ & $\ldots$ & $\ldots$ & $\ldots$ & $\ldots$ & $\ldots$ & $\ldots$ & $\ldots$ & $\ldots$ & $\ldots$ & $\ldots$ & $\ldots$ \\
\hline
\end{tabular}

used a Random Forest classifier as a predictive model, however, the usage of other algorithms is also possible. To build the predictive model for the year $m$, we use information about students, their choices and their performance for previous years $m-1, m-2, \ldots$ as a training dataset. Next, using corresponding information about students for the year $m$, we predict their choices. To obtain predictions of multiple choices, we select top- $N$ most probable subjects according to the model's output. In this paper, we perform evaluations for $N=2$ and $N=3$. We refer to this stage as Step $\mathbf{1}$ prediction.

On Step 2 prediction the students are distributed between relevant examination centers and their choices are aggregated by subjects. Finally, on Step 3 we perform final aggregation to estimate the required number of professors. For this, we divide the number of times every subject was chosen by the number of students a professor can examine during a one-day session, see note ${ }^{* *}$ for Table 2. If a resulting number is not an integer, we round it using ceiling function. We also ensure that there is at least 1 professor of every subject.

Step 1, step 2, and step 3 produce predictions that can be compared with the corresponding real values. Although only the output of step 3 is required 


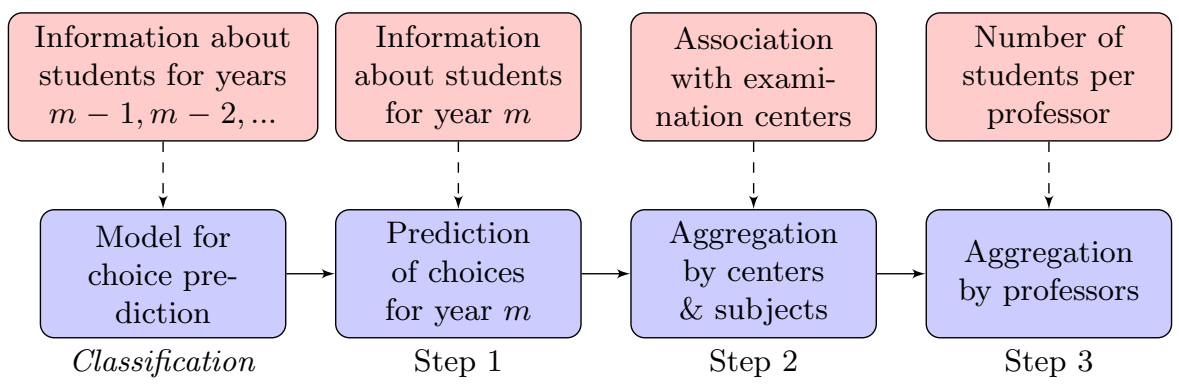

Fig. 2: BacAnalytics architecture.

for the organization of the remedial test, in the next section we evaluate the performance of BacAnalytics on all 3 steps. This allows us to understand better the performance of the tool and identify possible ways of improvement.

\subsection{Tool Evaluation}

Metrics. To evaluate the performance of the predictive models, we use accuracy (acc) as the main metric. The value of accuracy is defined as a fraction of the number of correctly predicted instances (\#corr) to the total number of instance to be predicted (\#to_predict), see equation (1). Additionally, as in our evaluation we use $N>2$, some of the predictions will be redundant. We evaluate redundancy (red) of a model according to the formula in equation (2).

$$
\text { acc }=\frac{\# \text { corr }}{\# \text { to_predict }} \quad \text { (1) } \quad \text { red }=\frac{\# \text { predicted }- \text { \#corr }}{\text { \#predicted }}
$$

Step 1: per-student prediction. We evaluate the performance of predictions on step 1 in two ways: how accurately the model can predict at least 1 subject of the student's choice $(c=1)$ and both of them $(c=2)$. Corresponding results for 2018 are presented in Fig. 3. We can see that even when taking only 2 predicted subjects $(N=2)$, the model is quite accurate in $c=1$ scenario, with the lowest accuracy being 0.93 for STMG stream of BTN. However, the performance drops significantly if we require both choices to be predicted correctly $(c=2)$. The lowest accuracy, in this case, is 0.28 for STL stream of BTN and the highest value of accuracy for all streams does not exceed 0.56 . For $N=3$ overall performance increases. Accuracy of prediction of at least 1 subject comes very near to 1 for most of the streams, except STMG with corresponding value of 0.96. Accuracy for $c=2$ also increases, however, for streams STL and STMG it is below 0.6. Thereby, we can conclude that the model stays unable to reliably predict both choices of students. Generally, prediction model performs better for BGN with ES stream having the lowest prediction accuracy. As for BTN, the predictive model struggles the most with STL and STMG streams. 


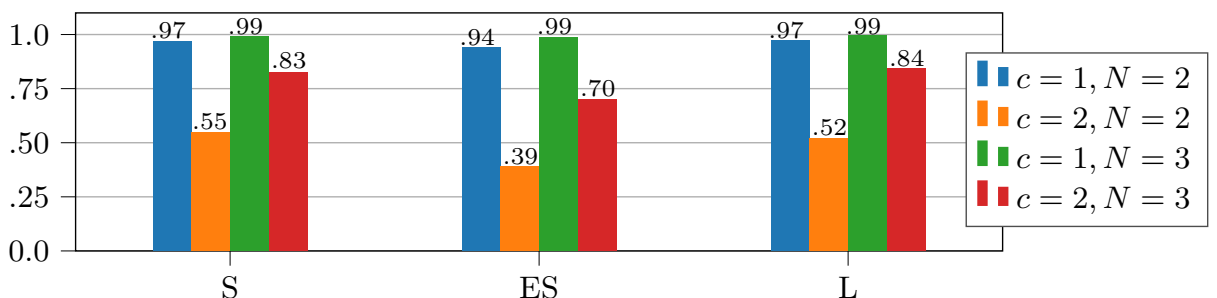

(a) BGN

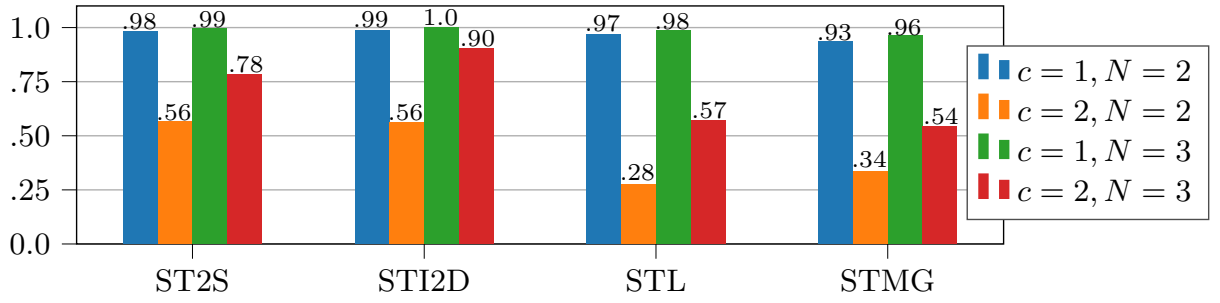

(b) BTN

Fig. 3: Accuracy of step 1 prediction for 2018.

Step 2: per-subject prediction. To evaluate the results of step 2 prediction, we use both accuracy and redundancy. The results for 2018 are presented in Fig. 4. We can notice a considerable improvement in performance as compared to the results of step 1 for prediction of 2 choices $(c=2)$. $N=2$ scenario results on average in $a c c=0.89$ and red $=0.11$. For $N=3$, we can predict the number every subject is chosen with an average accuracy of 0.98 . This also comes at a cost of increased redundancy with the average value of 0.34 . On the opposite, the corresponding value of accuracy for $c=2, N=3$ scenario of step 1 prediction is only 0.74 . Such improvement is explained by the fact that when performing aggregation per subject, some incorrect predictions can compensate each other. For example, if student $i$ chose mathematics and French and student $j$ chose geography and philosophy, then predicting mathematics and philosophy for student $i$ and geography and French for student $j$ results in absolutely correct per-subject prediction.

Step 3: per-professor prediction. The most important and practically useful indicator of BacAnalytics performance is the evaluation of predictions on step 3. The corresponding results for 2018 are given in Fig. 5. We can see further performance improvement. For instance, for $N=2$ the average accuracy is equal to 0.95 and the average redundancy to 0.08 . When we increase the value of $N$ to 3, BacAnalytics can correctly predict the number of required professors for all streams but STMG of technological baccalaureate with the corresponding value of accuracy being 0.96 . The average value of redundancy, in this case, is 0.25 which is a significant reduction as compared to red $=0.35$ for step 2 prediction with $N=3$. The reason for this improvement is error compensation due to further aggregation. For example, if the French language was chosen by 


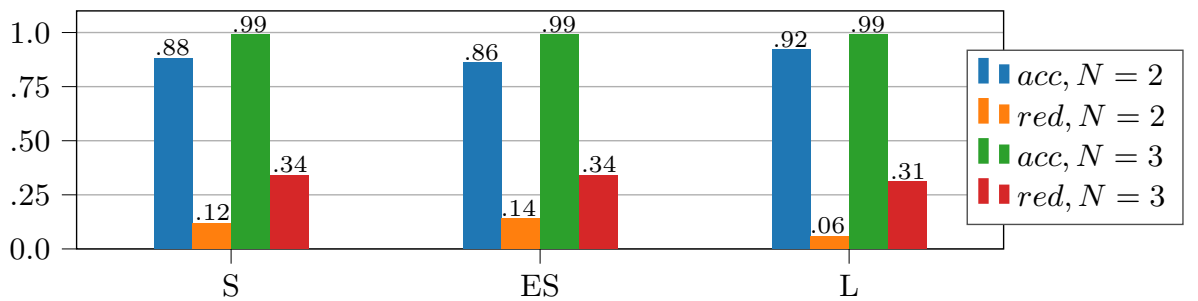

(a) BGN.

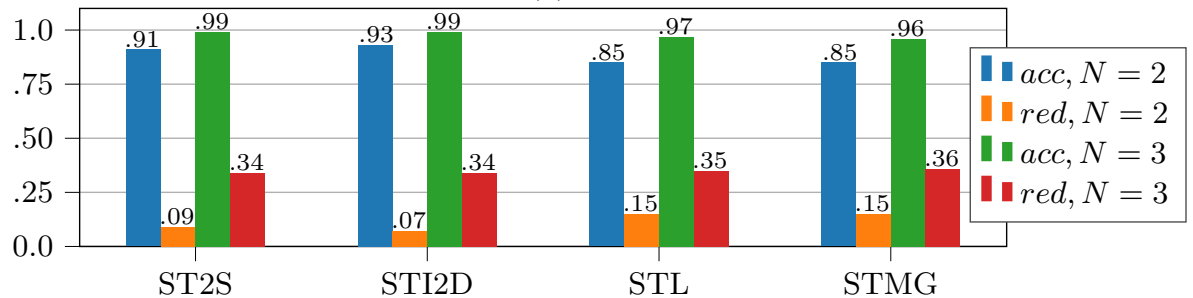

(b) BTN.

Fig. 4: Accuracy and redundancy of step 2 prediction for 2018.

12 students in reality and BacAnalytics estimated this value to be 8 , then perprofessor aggregation will result in the same number of required professors that is equal to 2, as 1 professor of French can examine 7 students, see note ${ }^{* *}$ for Table 2. Overall, we can conclude that the results obtained by BacAnalytics with $N=3$ are good enough to be used in practice. This statement is also supported by the final results obtained for the year 2019 with only a minor decrease in accuracy, see Fig. 6.

\subsection{Impact of BacAnalytics}

As mentioned before, BacAnalytics was developed in collaboration with the Acamedy of Nancy-Metz in Grand Est region of France. After preliminary model evaluation on the data for years 2013-2017, the tool was used during the preparation of the remedial test in 2018 and 2019. Given the nature of the application, the rectorate of the academy decided to use $N=3$ as a default value. As was shown above, such settings resulted in quite accurate predictions. In general, both professors and administration reported a more peaceful and enjoyable experience. BacAnalytics was also awarded the national French prize Impulsion 2018 in nomination "Innovation".

\footnotetext{
$\overline{7}$ http://www.ac-nancy-metz.fr/prix-impulsions-2018-1-8217-academie-de-nancy-m etz-primee-au-niveau-national--120140.kjsp,

https://www.education.gouv.fr/cid136476/trois-laureats-primes-au-prix-impulsio ns-2018-de-la-modernisation-participativeprixduprojetinnovant.html
} 


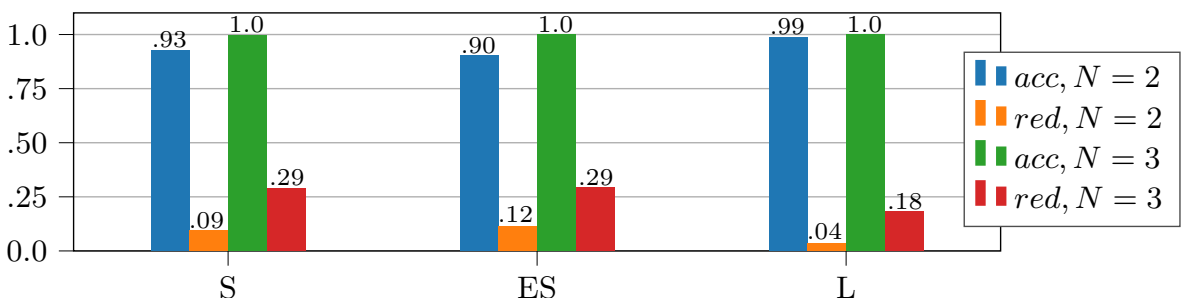

(a) BGN

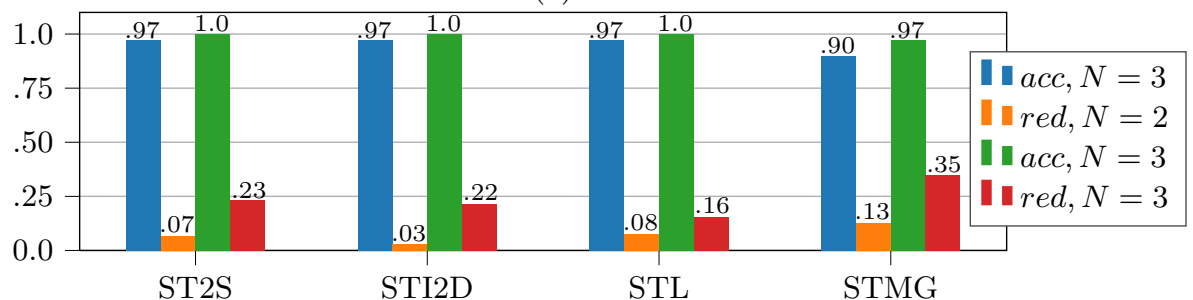

(b) BTN

Fig. 5: Accuracy and redundancy of step 3 prediction for 2018.

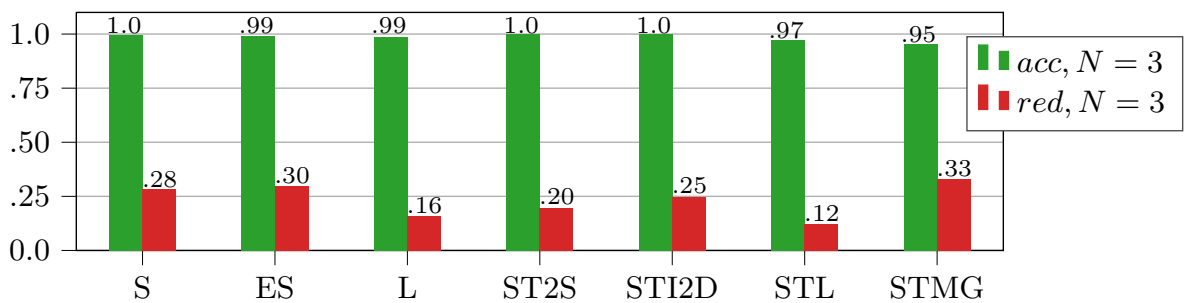

Fig. 6: Accuracy and redundancy of step 3 prediction for 2019, $N=3$.

\section{Conclusions and Future Work}

This paper presents BacAnalytics - a tool that was developed to assist in the preparation of the remedial test for the French secondary school examination called baccalauréat. The baccalauréat system allows the students to announce the subjects to be retaken on the day of the remedial test. Given that all examinations on this day are oral, a large number of professors have to be mobilized to fulfill the possible demand. BacAnalytics utilizes historical information about students' choices to estimate the number of required professors. It achieves almost $100 \%$ prediction accuracy at the price of approximately $25 \%$ redundancy. This tool was successfully employed by the Academy of Nancy-Metz in the years 2018 and 2019 and was awarded a French national prize in nomination "Innovation".

The evaluation results presented in the paper show, however, that the tool can be improved. Some of the baccalauréat series are more difficult to prediction than others. In future work, we consider constructing more refined models for 
these cases. Additionally, we want to use the approaches of error-aware data mining to incorporate the feedback and further improve the results.

\section{References}

1. Baepler, P., Murdoch, C.J.: Academic analytics and data mining in higher education. International Journal for the Scholarship of Teaching and Learning 4(2), 1-9 (2010)

2. Durand, G., Goutte, C., Belacel, N., Bouslimani, Y., Léger, S.: A diagnostic tool for competency-based program engineering. In: Proceedings of the 8th International Conference on Learning Analytics and Knowledge. pp. 315-319 (2018)

3. Heo, J., Lim, H., Yun, S.B., Ju, S., Park, S., Lee, R.: Descriptive and predictive modeling of student achievement, satisfaction, and mental health for data-driven smart connected campus life service. In: Proceedings of the 9th International Conference on Learning Analytics \& Knowledge. pp. 531-538 (2019)

4. King, K.G.: Data analytics in human resources: A case study and critical review. Human Resource Development Review 15(4), 487-495 (2016)

5. Lauría, E.J., Moody, E.W., Jayaprakash, S.M., Jonnalagadda, N., Baron, J.D.: Open academic analytics initiative: initial research findings. In: Proceedings of the Third International Conference on Learning Analytics and Knowledge. pp. 150-154 (2013)

6. Lawson, C., Beer, C., Rossi, D., Moore, T., Fleming, J.: Identification of 'at risk'students using learning analytics: the ethical dilemmas of intervention strategies in a higher education institution. Educational Technology Research and Development 64(5), 957-968 (2016)

7. Morsy, S., Karypis, G.: A study on curriculum planning and its relationship with graduation gpa and time to degree. In: Proceedings of the 9th International Conference on Learning Analytics \& Knowledge. pp. 26-35 (2019)

8. Patil, S., Nemade, V., Soni, P.K.: Predictive modelling for credit card fraud detection using data analytics. Procedia computer science 132, 385-395 (2018)

9. Romero-Zaldivar, V.A., Pardo, A., Burgos, D., Kloos, C.D.: Monitoring student progress using virtual appliances: A case study. Computers \& Education 58(4), 1058-1067 (2012)

10. Van Barneveld, A., Arnold, K.E., Campbell, J.P.: Analytics in higher education: Establishing a common language. EDUCAUSE learning initiative 1(1), l-ll (2012)

11. Viberg, O., Hatakka, M., Bälter, O., Mavroudi, A.: The current landscape of learning analytics in higher education. Computers in Human Behavior 89, 98-110 (2018)

12. Zhou, K., Fu, C., Yang, S.: Big data driven smart energy management: From big data to big insights. Renewable and Sustainable Energy Reviews 56, 215-225 (2016)

13. Zhu, L., Yu, F.R., Wang, Y., Ning, B., Tang, T.: Big data analytics in intelligent transportation systems: A survey. IEEE Transactions on Intelligent Transportation Systems 20(1), 383-398 (2018) 